\title{
Experimental Study on the Parameters Effect on the Sampling Method Based on Negative Pneumatic Conveying
}

\author{
Hongtu Zhang 1, 2,3, Jianping Wei 1, 2,3, Yungang Wang 1,2,3*, Zhihui Wen 1, 2,3 \\ and Banghua Yao ${ }^{1,2,3}$ \\ ${ }^{1}$ State Key Laboratory Cultivation Base for Gas Geology and Gas Control, Henan Polytechnic \\ University, Jiaozuo 454000, Henan, P. R. China \\ ${ }^{2}$ School of Safety Science and Engineering, Henan Polytechnic University, Jiaozuo 454000, \\ Henan, P. R. China \\ ${ }^{3}$ Coal Production Safety Collaborative Innovation Center in Henan Province, Jiaozuo 454000, \\ Henan, P. R. China \\ E-mail: wyg@hpu.edu.cn
}

\begin{abstract}
The factors of pipe diameter, drilling velocity and the degree of hole collapse effects on vacuum pneumatic conveying were studied by the self-developed vacuum pneumatic conveying experimental system. The results revealed the following three facts. 1) for a certain external diameter $73 \mathrm{~mm}$, the best choice for the inner diameter was $36 \sim 46 \mathrm{~mm}$; 2) when the drilling velocity was below $0.44 \mathrm{~m} / \mathrm{min}$, the total pressure drop in the system is low and the sampling time cost is moderate; 3 ) for reducing the particle breakage ratio during the process of vacuum pneumatic conveying for sampling with a $50 \mathrm{~m}$ distance, the roots vacuum pump with a pressure range above $40 \mathrm{kPa}$ and air flow rate of about $1000 \pi D^{2} \mathrm{~m}^{3} / \mathrm{min}$ was required. The above results provide a suggestion for coal sampling based on the vacuum pneumatic conveying parts selection.
\end{abstract}

Keywords: Drill pipe inner diameter, Drilling velocity, Negative pneumatic conveying, Particle breakage ratio.

\section{INTRODUCTION}

Coalbed methane is a potential source of energy reserved in the coal seam. This reserve also causes serious disasters with loss of life and personal injury around the world, and especially in mainland China due to the complexity of its reservoir conditions $[1,2]$. In order to exploit the coalbed methane and maintain the reservoir content while reducing coal mine disasters, determining the methane content accurately is an essential advance step [3]. However, sampling from the targeted location is a challenge for determining the methane content accurately in the coal industry. There are two main methods applied to sample from the targeted location. One method is sampling based on the pneumatic conveying. The other is sampling based on core tube. The former is widely used for the short amount of time needed and its ease of operation. The pneumatic conveying methods includes two types classified by the power resource; i.e., positive pressure pneumatic conveying and negative pressure pneumatic conveying. In the positive pressure pneumatic conveying process, compressed air flows in the internal portion of the drill pipe to the bottom of the borehole and carries the drilling cuttings through the annular region between the borehole and out of the dill pipe. The drilling cuttings are then sampled by a special device. However, this method yields a low level of purity in the samples because they include some portions exposed for long periods of time, causing a large rate of error in the determination of gas loss content [4, 5] .Recently, the method based on negative pressure pneumatic conveying has been presented due to its ability to avoid the shortcoming of low sample purity, which is also considered a promising method to accurately determine the coal bed methane content $[6,7]$.To date, according to the authors' knowledge, there are insufficient detailed studies about the factors affecting the sampling process based on the negative pressure pneumatic conveying.

There are two ways to study this issue; i.e., the experimental study and the theoretcal study. The computational fluid dynamic simulation has been widely employed recently [8-12] and the experimental study has been widely used as a tool to validate the computational fluid dynamic simulation result. In this study, firstly a detailed study about the factors affecting the sampling process based on negative pressure pneumatic conveying (SPNPPC) was carried out using the self-developed experimental device, specifically the drilling pipe inner diameter, drilling velocity, the effective air flow area and the coal particle breakage ratios. Then the power device used in the sampling method 
based on the negative pressure pneumatic conveying was selected based on the former step.

\section{PRESSURE DROP IN SPNPPC}

A vacuum pump is selected as the power device to provide the energy consumption of air-particle flow in the whole sampling process. The air flows are driven by the vacuum pump from the borehole inlet to the borehole bottom, carrying the drilling cuttings into the drill pipe inner portion through the fluid hole in the pit. In the drill pipe inner portion, the drilling cuttings are accelerated by air to a steady velocity and moves with the air in a relatively steady motion to the sampling device. In the sampling process, the energy consumption is equal to the pressure drop. The whole pressure drop $\Delta P$ is mainly divided into two parts; i.e., the air phase causing the pressure drop $\Delta P_{\mathrm{g}}$ and the particle phase causing pressure drop $\Delta P \mathrm{~s}$. Each includes four parts; accelerating pressure drop, suspension and elevating pressure drop, friction pressure drop and local pressure drop. Generally, the accelerating pressure drop is small compared with the other parts and is therefore ignored. As for the horizontal with uniform inner diameter drill pipe, the suspension and elevating pressure drop and local pressure drop are both small and is therefore ignored. The friction pressure drop caused by the air-particle flow is considered in this study.

According to the additional pressure drop [13], the frictional pressure drop described in air velocity is as follows:

$\Delta P_{m f}=\Delta P_{s}+\Delta P_{g}$

$\Delta P_{s}=m \lambda_{s} \frac{\rho_{g} v_{g}^{2}}{2 D} L$

$\Delta P_{g}=\lambda_{g} \frac{\rho_{g} v_{g}^{2}}{2 D} L$

Where, the $\Delta P \mathrm{~s}, \Delta P_{\mathrm{g}}$ is the particle frictional pressure drop and the gas frictional pressure drop respectively; $\mathrm{Pa} ; \mathrm{m}$ is the solid-gas ratio; $\lambda_{s}, \lambda_{\mathrm{g}}$ is the particle frictional coefficient and the gas frictional coefficient respectively. $L$ is the pipe length, $\mathrm{m} ; D$ is the pipe inner diameter, $\mathrm{m} ; \rho_{\mathrm{g}}$ is the gas density, $\mathrm{kg} / \mathrm{m}^{3} ; v_{\mathrm{g}}$ is the gas velocity, $\mathrm{m} / \mathrm{s}$.

The particle frictional coefficient $\lambda_{s}$ is described as follows:

$\lambda_{s}=2.1 m^{0.3} \sqrt{F r_{t}} F r^{-2}\left(\frac{D}{d_{s}}\right)^{-0.1}$

$F r_{t}, F r$ is the particle Froude and gas Froud

$$
\begin{aligned}
& F r_{t}=u_{t} / \sqrt{g d_{s}} \\
& F r=v_{g} / \sqrt{g D} \\
& u_{t}=1.74 / \sqrt{\frac{d_{s}\left(\rho_{s}-\rho_{g}\right) g}{\rho_{g}}}
\end{aligned}
$$

$u_{\mathrm{t}}, d_{\mathrm{p}}$ is the particle suspension velocity and the diameter; $\rho_{\mathrm{p}}$ is the particle density, $\mathrm{kg} / \mathrm{m}^{3}$
$\lambda_{g}=0.0125+\frac{0.0011}{D}$

The total pressure drop is:

$\Delta P=\Delta P_{m f}+\Delta P_{s}=\rho_{g}\left[1.39 \mathrm{~m}^{1.3} d_{s}^{-0.4} D^{-0.1} \rho_{g}^{0.25} g^{0.5}\left(\rho_{s}-\rho_{g}\right)^{-0.25} L+\right.$

$\left(0.00625+0.00055 D^{-1}\right) L D^{-1} v_{g}^{2}$

From Eq.(9), the factors affecting the total pressure drop is particle diameter $d_{\mathrm{p}}$, particle-gas ratio $\mathrm{m}$, pipe length $L$ and the inner diameter $\mathrm{D}$ and the gas velocity $v_{\mathrm{g}}$

\section{EXPERIMENTAL DEVICE AND METHOD}

\subsection{Experimental device}

The experimental device developed for the sampling method based on the negative pressure pneumatic conveying is shown in Figure 1, including the vacuum pump, sample collection device, parameters testing device, static equivalent pipe, dynamic equivalent pipe, equivalent pit and feed device.

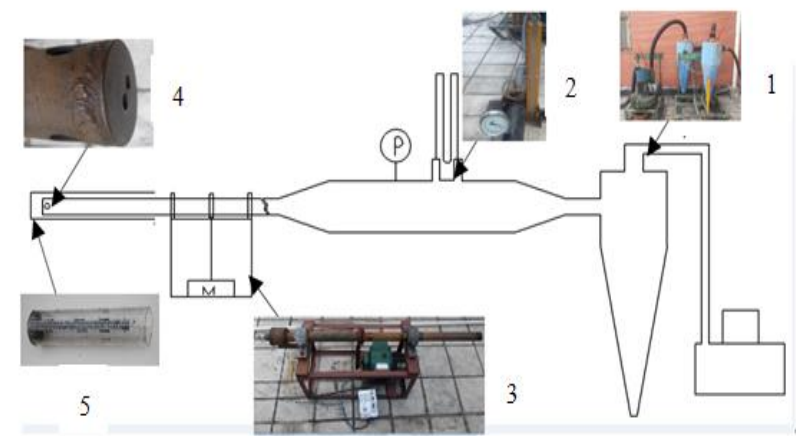

1. sampling collection device 2. parameters testing device

3. dynamic equivalent pipe 4 . equivalent pit 5 . feed device

Figure 1. Experimental device scheme

Sample collection device. In this study, the cyclone was selected as a sample collection device for its high collection efficiency and ease of operation. However, the outlet of the cyclone is connected to the vacuum pump which is easily contaminated with dust Therefore, a two cyclones series connections structure has been implemented to reduce the dust ratio of the outlet gas.

Parameters testing device. The main parameters are pressure drop and air flow rate of the gas-solid flow system. A high precision vacuum gauge with a precision grade of 0.25 was employed to test the whole pressure drop. Orifice plate flowmeter is widely used in natural gas transportation and other gas flowrate measuring processes and can also be employed to determine the gas flowrate in gas-solid flow because the solid effect on the pressure drop of the two sides of orifice plate flowmeter is ignored [9-10]. The type of DN100-1/2 orifice plate flowmeter and " $U$ " tube placed in a pipe made according to [11] were employed to test the gas flow rate and the pressure drop.

Dynamic equivalent pipe. The drill pipe with pit rotates at a speed of about 220rpm and the drilling cuttings are 
continuously carried by the air flow into the inner portion of the drill pipe through the hole in pit. On the other side, the rotation of the drill pipe has the benefit on reducing the risk of depositing coal particles. The dynamic equivalent pipe includes five parts; i.e., real drill pipe, antifriction bearing, belt pulley, electro-magnetic speed adjustable motor and support. A real drill pipe with an inner diameter of $40 \mathrm{~mm}$ and a length of $2 \mathrm{~m}$ was employed. Two antifriction bearings and one belt pulley were placed on the two sides and middle side respectively. The belt pulley was connected with a electromagnetic speed adjustable motor. All the above parts were placed on the support.

Static equivalent pipe. Though the rotating pipe at a certain speed is the real condition, it remains dificult to conduct a device with a length up to $50 \mathrm{~m}$. The PIV tube was employed as the main pipe part, for it can easily regulate the length and the inner diameter. The inner diameters were $26 \mathrm{~mm}, 36 \mathrm{~mm}$, $46 \mathrm{~mm}$.

Equivalent pit. On one dynamic equivalent pipe side, five holes were drilled with dimensions equivalent to the real pit with an external diameter of $94 \mathrm{~mm}$, and the PDC pit is available as an alternative. Compared with using a real pit, the equivalent pit has the advantages of easy operation and low cost.

Feeder device. In other pneumatic conveying experiment systems, screw feeders were widely used for the subject as just some certain solids pneumatic conveying at special operation conditions with steady feed speeds. In the sampling method based on negative pressure pneumatic conveying, the drilling cuttings were fed with the drilling pipe moving forward. Organic glass tube with an inner diameter of $100 \mathrm{~mm}$ and with ruler embodied on the external face was used, and the speed of the drilling pipe moving forward was controlled.

\subsection{Coal particle diameter selection}

Three coal samples were taken from the workface 11204 of the Xinan coal mine with a high risk of coal and gas outburst, and the samples were sieved. The particle size distribution is classified as in Table 1.

Table 1.The particle size distribution of samples

\begin{tabular}{lllllll}
\hline \multirow{2}{*}{ size/mm } & $<0.2$ & $\begin{array}{l}0.2 \sim \\
0.25\end{array}$ & $\begin{array}{l}0.25 \sim \\
0.5\end{array}$ & $0.5 \sim 1$ & $>1$ \\
\hline \multirow{2}{*}{$\mathrm{S}_{1}$} & mass/g & 51.3 & 24.2 & 65.3 & 237.1 & 20.4 \\
& ratio/\% & 12.88 & 6.07 & 16.39 & 59.52 & 5.12 \\
\multirow{2}{*}{$\mathrm{S}_{2}$} & mass/g & 49.5 & 23.1 & 60.8 & 241.1 & 30.4 \\
& ratio/\% & 12.22 & 5.71 & 15.02 & 53.81 & 7.51 \\
\multirow{2}{*}{$\mathrm{S}_{3}$} & mass/g & 54.2 & 19.8 & 72.1 & 258.9 & 19.7 \\
& ratio/\% & 12.76 & 4.66 & 16.98 & 60.96 & 4.63 \\
\hline
\end{tabular}

From Table 1, the particle with a diameter of $0.5-1 \mathrm{~mm}$ accounts for up to $60 \% \sim 70 \%$ of the whole sample mass. In Eq.(9), the larger the particle diameter, the higher the pressure drop. In order to successfully obtain the samples employing the negative pressure pneumatic conveying method, the capability of the vacuum pump should be able to sample the particles out. In this study, the particle diameter is set at $0.5 \sim 1 \mathrm{~mm}$.

\section{RESULTS AND DISCUSSIONS.}

\subsection{Drill pipe diameter}

In Eq.(9), at the same operating conditions, the whole system pressure drop has a negative relationship with the drill pipe diameter. The whole pressure drop of pure gas flow in the pipes with an inner diameter of $\phi 26 \mathrm{~mm}, \phi 36 \mathrm{~mm}, \phi$ $46 \mathrm{~mm}$ is shown in Figure 2.

Figure 2 shows that the whole pressure drop decreases with the increasing of the drill pipe diameter. In the vacuum performance curve, the air flow rate has a negative relationship with the static pressure and the wind resistance. Increasing the drill pipe diameter can reduce the wind resistance, thus increasing the air flow rate. In Eq.(3), the pressure drop induced by the pure gas has a square relationship with the gas velocity. However, the pressure drop change with increasing the drill pipe inner diameter plays a prominent role in deceasing the wind resistance than that of increasing the air flow rate.

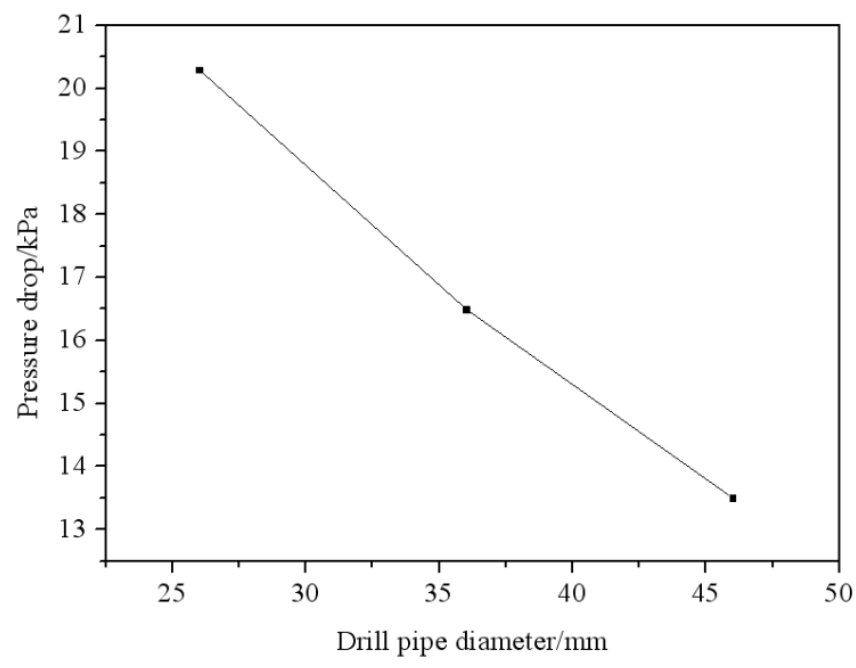

Figure 2. Effect of pipe diameter on the pressure drop

On one hand, increasing the drill pipe inner diameter can reduce the pressure drop. On the other hand, in the sampling method based on the negative pressure pneumatic conveying, the drill pipe also transmits a large amount of torque to drive the pit to cut the coal wall, especially in the case of soft coal seam. In order to reduce the risk of losing drill tools, the drill pipe should have high strength, generally taking section modulus in torsion into consideration .The section modulus in torsion is described as follows:

$W_{p}=\frac{\pi D^{3}}{16}\left(1-\frac{d^{4}}{D^{4}}\right)$

where, $W_{\mathrm{p}}$ is section modulus in torsion; $D$ is drill pipe external diameter, $\mathrm{m}$; $d$ is drill inner diameter, $\mathrm{m}$.

From Eq.(10) and Figure 2, it is reasonable to conclude that the drill pipe diameter ranges from $36 \mathrm{~mm}$ to $46 \mathrm{~mm}$ with a external diameter $73 \mathrm{~mm}$.

\subsection{Drilling velocity}

In Eq.(9), the pressure drop has a linear relationship with the $\mathrm{m}$. $\mathrm{m}$ as a key parameter equals to the ratio of the solid 
mass to gas mass in a certain time. $m$ can be described as follows:

$\mathrm{m}=\frac{\mathrm{m}_{\mathrm{c}}}{\mathrm{m}_{\mathrm{g}}}=\frac{n \rho_{s} v D^{2}}{\rho_{g} v_{g} d^{2}}$

Where $\mathrm{m}$ is the solid-gas ration; $\mathrm{m}_{\mathrm{c}}$ is the coal flow mass, $\mathrm{kg} / \mathrm{min} ; \mathrm{m}_{\mathrm{g}}$ is the gas flow mass, $\mathrm{kg} / \mathrm{min}$; $\mathrm{n}$ is the ratio of real coal mass to the calculating coal mass; $v, v_{\mathrm{g}}$ is drilling velocity and gas velocity respecially, $\mathrm{m} / \mathrm{min} ; D, d$ is pit diameter and drill pipe inner diameter, respectively.

Usually the PDC pit diameter is $94 \mathrm{~mm}$ and the coal density $1400 \mathrm{~kg} / \mathrm{m}^{3}$, thus coal mass of length $1 \mathrm{~m}$ equals to $9.7 \mathrm{~kg}$ in theory. However, the real coal mass is up to $3 \sim 6$ times the theory mass [14]. This study conducted three experiments, feeding the same coal mass $1.5 \mathrm{~kg}$ in four different times; i.e., $14 \mathrm{~s}, 10 \mathrm{~s}, 7 \mathrm{~s}, 4 \mathrm{~s}$, the corresponding drilling velocity is $0.22 \mathrm{~m} / \mathrm{min}, 0.31 \mathrm{~m} / \mathrm{min}, 0.44 \mathrm{~m} / \mathrm{min}, 0.77 \mathrm{~m} / \mathrm{min}$ respectively.

The pressure drop results with a drill pipe diameter of $36 \mathrm{~mm}$ is depicted in Figure 3.

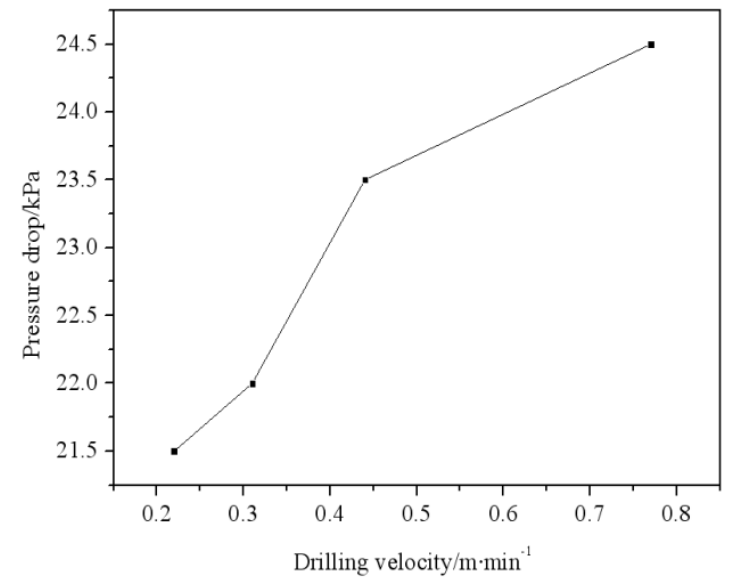

(a) Drilling velocity effect on pressure drop

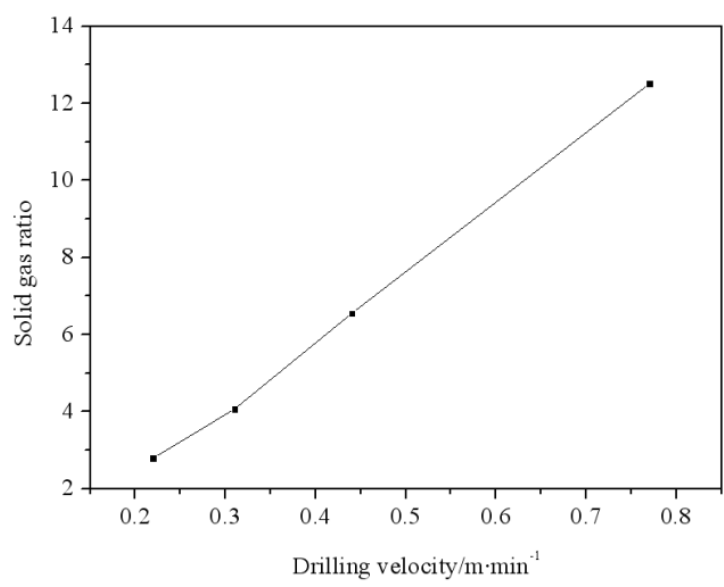

(b) Drilling velocity effect on solid gas ratio

Figure 3. Effect of drilling velocity on conveying process

Figure 3 shows that when the drilling velocity ranges from $0.22 \mathrm{~m} / \mathrm{min}$ to $0.44 \mathrm{~m} / \mathrm{min}$, the solid-gas ratio is below 10 and the flow system dilutes the pneumatic conveying and the pressure drop increment is small. When the drilling velocity is up to $0.77 \mathrm{~m} / \mathrm{min}$ with solid-gas ratio $\mathrm{m}$ up to 18.29 , the flow system approximates a dense pneumatic conveying. The collisions between coal particles and particle-wall increase.
At the same time, the effective area of air flow decreases, thus contributing to the pressure drop increasing and the air flow rate decreasing. The air flow rate decreasing easily results in coal particle deposition.

\subsection{The collapse degree of borehole}

The air flow effective area also is affected by the degree of collapse of the borehole, especially in the soft coal seam which has detrimental drilling conditions [15].The larger the degree of borehole collapse, the air flow rate becomes lower, and thus easily results in coal particle deposition in the pit portion. The five fluid holes were closed by plastic scotch tape under different conditions to simulate the degree of borehole collapse as depicted in Figure 4.

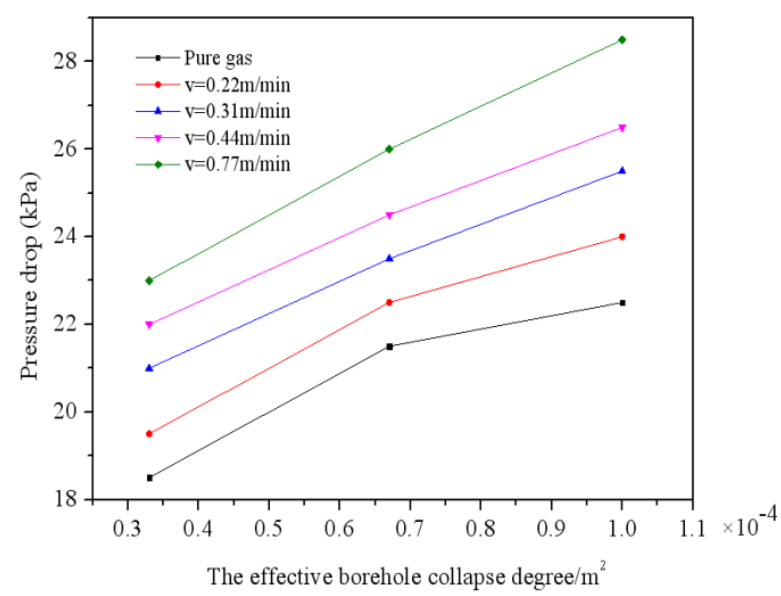

Figure 4. Effect of borehole collapse degree on the pressure drop

Pressure drop decreases with the air flow effected area enlarged under the same drilling velocity due to the increasing drill pipe inner diameter. At times, because the real coal mass is three times the theory coal mass, the fluid holes of the pit were easily blocked which can lead to the borehole collapse to some degree. The whole pressure drop was higher even under the lowest degree of borehole collapse. In other words, the higher the drilling velocity, the higher degree of equivalent borehole collapse.

\subsection{Particle breakage ratio}

In the pneumatic conveying process, particle breakage or attrition will occur especially for fragile material such as deformed soft coal particles when the normal interaction force for particle-particle, particle-wall particle exceeds the strength. As for the sampling method based on the negative pressure pneumatic conveying, the particle size degraded to some degree [16-18] the main influencing factors being gas velocity, solid-gas ratio and coal strength. The particle breakage " $\eta$ " is definite as:

$\eta=\frac{\mathrm{m}_{<\mathrm{d}}}{\mathrm{m}_{\mathrm{d}}} \times 100 \%$

where, $\mathrm{m}_{<\mathrm{d}}$ is the mass of particle with diameter below $\mathrm{d}, \mathrm{kg}$; $\mathrm{m}_{\mathrm{d}}$ is the mass of particle with diameter $\mathrm{d}, \mathrm{kg}$. 


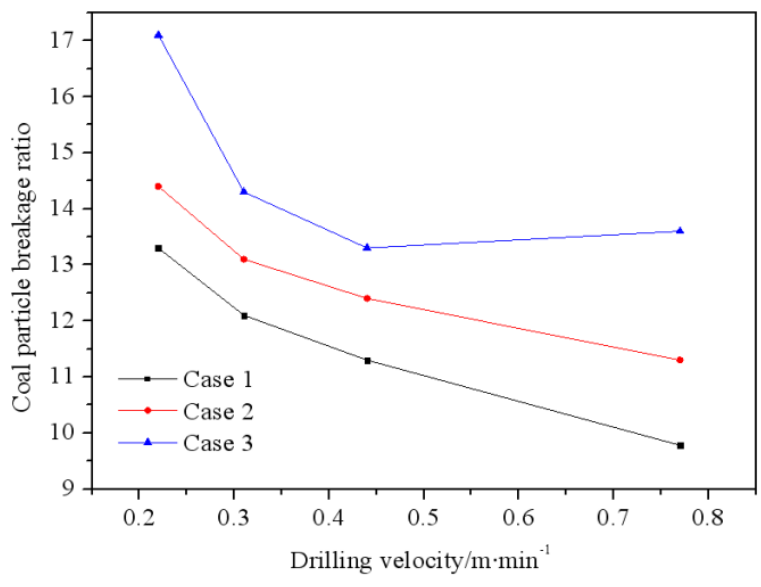

Figure 5. Particle breakage ratio under different working conditions: case 1 is all the fluid borehole of fit open, case 2 is with one of the fluid borehole of fit closed, case 3 is with two of the fluid borehole of fit closed

Figure 5 shows that the coal particle breakage ratio ranges from $12.15 \% \sim 17.13 \%$. When the drilling velocity is $0.22 \mathrm{~m} / \mathrm{min}$, the gas-coal particle flows with high gas velocity and low solid-gas ratio. The coal particle has larger kinetic energy in the steady flow stage and higher normal force induced by the interaction of the coal particle-wall. For a low solid-gas ratio, the interaction of particle-particle was ignored. The interaction of particle-wall plays a main role in the coal particle breakage process. When the drilling velocity reaches up to $0.77 \mathrm{~m} / \mathrm{min}$, the gas-coal particle flows with low gas velocity and high solid-gas ratio. The coal particle has lower kinetic energy in the steady flow stage. Though a high solid-gas ratio, the interaction of particle-particle should be considered. The effect of particle-particle interaction plays a little role in the coal particle breakage process [16-18] The particle breakage will affect the gas loss content calculation for the smaller particle size, and the faster of gas desorption velocity $[19,20]$. A relatively low gas velocity and solid-gas ratio should be adopted to reduce the coal particle breakage or attrition.

\section{VACUUM PUMP SELECTION}

The vacuum pump provides the gas-solid flow energy consumption, equating to the total pressure drop $\Delta P_{\mathrm{t}}$, in the sampling method based on the negative pressure pneumatic conveying. The gas-solid flow were divided into three parts in Figure 6, i.e., pure gas, solid-gas phase, and sample collection device, corresponding to the pressure drop $\Delta P_{g}, \Delta P_{s-g}, \Delta P_{c}$.

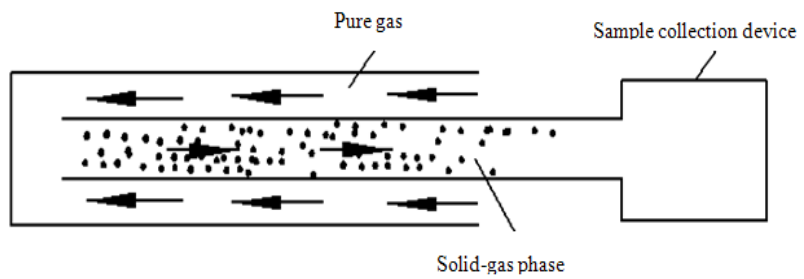

Figure 6. Pressure drop zones during the vacuum pneumatic conveying
$\Delta P_{g}$ is described in Eq.(13):

$\Delta P_{g}=\frac{1}{2} \lambda_{g} L / D_{a} \rho_{g} v_{a}^{2}$

where $\lambda_{\mathrm{g}}$ is friction coefficient; $L$ is the borehole length, $\mathrm{m}$; $D_{\mathrm{a}}$ is the annular diameter, $D_{\mathrm{a}}=0.021 \mathrm{~m} . \Delta P_{s-\mathrm{g}}$ is described in Eq.(9)

$\Delta P_{\mathrm{c}}$. is described in Eq.(14)-(15):

$\Delta P_{c}=\frac{\rho_{g} \xi v_{i n}^{2}}{2}$

$v_{\text {in }}=v_{\text {inner }} S_{d p} / S_{\text {in }}$

where, $\xi$ is friction coefficient; $v_{\text {in }}$ is the cyclone inlet velocity, $\mathrm{m} / \mathrm{s} ; v_{\text {inner }}$ is gas velocity in the inner drill pipe, $\mathrm{m} / \mathrm{s}$; $S_{d p}, S_{\text {in }}$ is drill pipe sectional area and cyclone inlet section area, respectively.

$\Delta P_{t}=\Delta P_{g}+\Delta P_{s-g}+\Delta P_{c}=$

$\rho_{g}\left[1.39 m^{1.3} d_{s}^{-0.4} D^{-0.1} \rho_{g}^{0.25} g^{0.5}\left(\rho_{s}-\rho_{g}\right)^{-0.25} L+\right.$

$L\left(0.00625+0.00055 D^{-1}\right) D^{-1} v_{g}^{2}$

$\left.+L\left(0.00625+0.00055 D_{\mathrm{a}}^{-1}\right) D_{\mathrm{a}}^{-1} v_{\mathrm{a}}^{2}+0.5 \xi v_{\mathrm{in}}^{2}\right]$

The minimum gas velocity $v_{\mathrm{m}}$ is described as follows:

$v_{m}=13.33 \mathrm{~m}^{0.25} \sqrt{g D}$

$\mathrm{m}=10, D=0.036 \sim 0.046, v_{\mathrm{m}}$ ranges from 14.09 to 15.92 and the $v_{\mathrm{m}}$ was set equals to $20 \mathrm{~m} / \mathrm{s}$.

In this study, the cyclone inlet diameter is twice than that of the drill pipe inner diameter. Correspondingly the velocity in the cyclone inlet is 0.25 times of that in the drill pipe inner diameter. When $v_{\mathrm{m}}$ equals $20 \mathrm{~m} / \mathrm{s}$, the cyclone pressure drop is approximately $0.5 \mathrm{kPa}[21]$.

In engineering practice, the samples taken from the distance of $30 \mathrm{~m}$ can be reflected the in suite character.

Taking, $L=50 \mathrm{~m} \rho_{\mathrm{s}}=1400 \mathrm{~kg} / \mathrm{m}^{3}, \rho_{\mathrm{g}}=1.2 \mathrm{~kg} / \mathrm{m}^{3}, d_{\mathrm{s}}=0.001 \mathrm{~m}$, $\mathrm{m}=10, D=0.036 \sim 0.046 \mathrm{~m}, v_{\mathrm{g}}=v_{\mathrm{m}}=20$ into the Eq.(17), the $\Delta P_{\mathrm{t}}=36.43 \sim 39.84 \mathrm{kPa}$. The function of the vacuum pump should meet the demand of static pressure above $40 \mathrm{kPa}$ and an air flow rate of approximately $1000 \pi D^{2} \mathrm{~m}^{3} / \mathrm{min}$.

\section{CONCLUSIONS}

In this paper, some factors affecting the negative pressure pneumatic conveying were studied by the self-developed experimental setup and conclusions could be drawn as follows:

1) The self-developed experimental device for the sampling method based on negative pressure pneumatic conveying performed well in the study well and the effects were studied.

2) The diameter ranges from $36 \mathrm{~mm}$ to $46 \mathrm{~mm}$ and the drilling velocity below $0.44 \mathrm{~m} / \mathrm{min}$ have been established as the suitable values for successfully sampling with an 
external diameter of $73 \mathrm{~mm}$

3) The gas velocity is the main cause of coal particle breakage and attrition during the sampling process and the optimum level was $20 \mathrm{~m} / \mathrm{s}$ in the inner drill pipe.

4) The function of the vacuum pump should meet the demand of a static pressure of above $40 \mathrm{kPa}$ and an air flow rate of approximately $1000 \pi \mathrm{D}^{2} \mathrm{~m}^{3} / \mathrm{min}$ for successfully sampling from a distance of $50 \mathrm{~m}$.

\section{ACKNOWLEDGEMENTS}

Financial support for this study was provided by the Fostering Foundation of Henan Polytechnic University for the Excellent Ph.D. Dissertation (72705/006), Foundation of Henan Educational Committee (14A440011), Key Project of Chinese Ministry of Education (No. 213022A), Fund for Science and Technology Innovation Talents of Henan Province (No. 164100510013), Research Fund for the Doctoral Program of Henan Polytechnic University (B050201), National Natural Science Foundation of China (No. 51304072, No. 51404100)are gratefully acknowledged.

\section{REFFERENCES}

[1] Bao Y., Wei C. and Neupane B., "Generation and accumulation characteristics of mixed coalbed methane controlled by tectonic evolution in Liulin CBM field, eastern Ordos Basin, China," Journal of Natural Gas Science and Engineering, vol. 28, pp. 262-270, 2016. DOI: 10.1016/j.jngse.2015.11.033.

[2] Wang H., Yao Y., Liu D., et al., "Fault-sealing capability and its impact on coalbed methane distribution in the Zhengzhuang field, southern Qinshui Basin, North China," Journal of Natural Gas Science and Engineering, vol. 28, pp. 613-625, 2016. DOI: 10.1016/j.jngse. 2015.12.036.

[3] Tian L., Cao Y., Chai X., et al., "Best practices for the determination of low-pressure/permeability coalbed methane reservoirs, Yuwu Coal Mine, Luan mining area, China," Fuel, vol. 160, pp. 100-107, 2015. DOI: 10.1016/j.fuel.2015.07.082.

[4] Wang Gang, Xie Jun, Duanyi, et al., "Direct method of determining gas content of coal beds from clastic coal core," Journal of Mining \& Safety Engineering, no. 04, pp. 610-615, 2013.

[5] Qi Liming, Chen Xuexi, Cheng Wuyi, et al., "Newly deveolped method for exact measurement of gas content," Journal of Mining \& Safety Engineering, no.01, pp. 111-115, 2010.

[6] Wei Jianping, Li Hui and Wang Yungang, "Gas content sampling method and device," 31 June, 2015, CN103225484A.

[7] Wu Zili, Kong Fanzheng and Sun Chongxu., "Study of the sampling methods of drill cuttings desorption index," Mining Safety \& Environment Protection, no.03, pp. 17-19, 1999.

[8] Bounaouara H., Ettouati H., Ticha H. B., et al., "Numerical simulation of gas-particles two phase flow in pipe of complex geometry: pneumatic conveying of olive cake particles toward a dust burner," International Journal of Heat and Technology, vol. 33, no.1, pp. 99-106, 2015. DOI: 10.18280/ijht.330114.

[9] Zhang Y., Zhou F., Xia T., et al., "Experimental investigation on blockage boundary for pneumatic conveying of powders in narrow bifurcation slits," Drying Technology, 2015, to be published.

[10] Kuang S. B., Li K., Zou R. P., et al., "Application of periodic boundary conditions to CFD-DEM simulation of gas-solid flow in pneumatic conveying," Chemical Engineering Science, vol. 93, pp. 214-228, 2013. DOI: 10.1016/j.ces.2013.01.055.

[11] Ebrahimi M., Crapper M and Ooi J. Y., "Experimental and simulation studies of dilute horizontal pneumatic conveying," Particulate Science and Technology, vol. 32, no.2, pp. 206-213, 2014. DOI: 10.1080/02726351.2013.851133.

[12] Lorenzini G., Helbig D., da Silva C.C.C, et al., "Numerical evaluation of the effect of type and shape of perforations on the buckling of thin steel plates by means of the constructal design method," International Journal of Heat and Technology, vol. 32, no. s1, pp. 9-20, 2016. DOI: 10.18280/ijht.34s102.

[13] Barth W., "Flow patterns during the conveyance of solid particles and droplets in gases," Chem. Ing. Tech, vol. 30, pp. 171-180, 1958.

[14] Yang Yongliang, Li Zenghua, Gao Wenju, et al., "Simulative experiment of pneumatic slag off for boreholes in coal seams," Journal of Mining \& Safety Engineering, vol. 4, pp. 415-418, 2006.

[15] Sun Yuning, Wang Yonglong, Zhai Xinxian, et al., "Analysis on reasons of drilling difficulty in soft and outburst coal seam," Journal of China Coal Society, vol, 37, no. 1, pp. 117-121, 2015. DOI: 10.13225/j.cnki.jccs.2012.01.025.

[16] Anantharaman A., Wu X., Hadinoto K., et al., "Impact of continuous particle size distribution width and particle sphericity on minimum pickup velocity in gassolid pneumatic conveying," Chemical Engineering Science, vol. 130, pp. 92-100, 2015, DOI: 10.1016/j.ces.2015.03.022.

[17] Liang C., Grace J. R., Shen L., et al., "An experimental investigation of pressure and cavitation characteristics of high velocity flow over a cylindrical protrusion in the presence and absence of aeration," Journal of Hydrodynamics, vol277, no.1, pp. 60-66, 2008. DOI: 10.1016/s1001-6058(08)60028-1u.

[18] Cui Y., Gao H., Sun J., et al., "Numerical simulation of gas-solid flow in a conveying vessel," Powder technology, vol. 226, pp. 34-42, 2012. DOI: 10.1016/j.powtec.2012.04.005

[19] Liu Yanwei and Liu Mingju., "Effect of particle size on difference of gas desorption and diffusion between soft coal and hard coal," Journal of China coal society, vol. 40, no.3, pp. 579-587, 2015. DOI: 10.13225 /j. cnki. jccs. 2014.0380.

[20] Nie Baisheng, Yang Tao, Li Xiangchun, et al., "Research on diffusion of methane in coal particles," Journal of China Univerdity of Mining \& Technology. vol. 42, no.6, pp. 975-981, 2013.

[21] Houben J.J.H., Weiss C., Brunnmair E., et al., "CFD simulations of pressure drop and velocity field in a cyclone separator with central vortex stabilization rod,' Journal of Applied Fluid Mechanics, vol. 9, no. 1, pp. 487-499, 2016. 